\title{
Measuring the Technical Efficiency of Airports in Latin America
}

\author{
Sergio Perelman \\ CREPP, University of Liege \\ Bd. du Rectorat 7 (B31), 4000 Liège, Belgium \\ +32 43663098, sergio.perelman@ulg.ac.be \\ Tomas Serebrisky ${ }^{1}$ \\ The World Bank \\ 1818 H Street NW, Washington DC 20433, USA \\ +1 202 458-2872, tserebrisky@worldbank.org
}

\begin{abstract}
Relying on a unique dataset this paper uses Data Envelopment Analysis methods to compute an efficient production frontier for a representative sample of Latin American airports. Latin America has implemented a wide variety of private sector participation schemes in the airport sector since the late 90s. To assess whether privately operated airports had higher rates of total factor productivity growth than public airports we compute Malmquist indexes for the period 2000-2007. Results indicate that privately operated airports enjoyed higher rates of total factor productivity growth.
\end{abstract}

\section{Keywords}

Airports, efficiency, Latin America

January, 2012

\footnotetext{
${ }^{1}$ Corresponding author: Tomás Serebrisky. The World Bank 1818 H Street NW, Washington DC 20433, USA +1 202 458-2872, tserebrisky@worldbank.org
} 


\subsection{Introduction}

During the last two decades there has been a growing interest in measuring the efficiency and performance of airports. On one hand, the process of introducing private participation in the management and operation of airports and the birth of regulatory agencies in charge of setting tariffs for the sector brought along the need to assess the way in which airports are being operated. On the other hand, with the liberalization of competition among airlines, airports started competing with each other for connecting traffic (to become hub airports) which prompted them to increase their efficiency.

This interest has spurred a growing literature aimed at estimating the efficiency of the airport sector. To the best extent of our knowledge, there has not been any study that computes the efficiency and performance of a representative sample of airports in Latin America (LAC). This region has implemented a wide variety of private sector participation schemes including concessions of several groups of airports (Mexico), a single concession of a group of airports with more than 90 percent of the air transport market (Argentina), single airport concessions (Chile), and a combination of single and group airport concessions (Peru). The introduction of private sector brought more than 9 billion dollars of investment to the sector between 1998 and $2008^{2}$. Several hypotheses can be provided to explain why airport efficiency in Latin America has not been the subject of academic research but the most likely reason is the lack of publicly available data.

The main objective of this paper is to fill this gap in the literature. We are able to do so using data collected from a questionnaire that was sent, as part of a World Bank study on

\footnotetext{
${ }^{2}$ Data obtained from the Public Private Infrastructure database, World Bank. Available at http://ppi.worldbank.org/
} 
airports, to the major airport operators in LAC (World Bank, 2010) ${ }^{3}$. It should be noted that the sample assembled for this study is representative of the air transport sector in the LAC region as it accounts for more than $80 \%$ of total passengers and aircraft movements in the region and for $70 \%$ of total air cargo. Table 1 lists the airports included in the sample, their type of ownership and passengers in 2008. Latin America and the Caribbean accounts for a small share of the air transport sector worldwide. Based on 2008 figures (World Bank, 2010) this region only accounted for 7 percent of total passengers, 5 percent of cargo and 8 percent of aircraft movements. Airports are relatively small when ranked on a global scale. LAC has a total of just 4 airports among the top 100 airports worldwide and 14 airports among the top 200. Benito Juárez International Airport in Mexico City, ranked 43rd globally, is the most important airport in the region in terms of passenger traffic, handling a total of about 26.2 million passengers in 2008 (approximately three times less than the number handled by first-ranked Hartsfield-Jackson Airport in Atlanta). As for cargo, the entire LAC region handled a total of 4.6 million metric tons in 2008, only 1 million metric tons more than the amount of cargo traffic handled by the global leader, Hong Kong International Airport (3.6 million metric tons) and three times as much as Miami, North America’s cargo hub (1.5 million metric tons).

[Table 1 app. here]

Table 2 presents descriptive statistics for the average LAC airport in our sample and compares it with the average airport in North America, Europe and Asia. Across size categories, airports in LAC have fewer passengers and aircraft movements. Airports in LAC tend to rely heavily on international passengers relative to airports in North America and Asia-Pacific. The

\footnotetext{
${ }^{3}$ The dataset is available upon request from corresponding author.
} 
most significant difference in output size between the average airport in LAC and that of the other regions is cargo. In terms of capital inputs, airports in LAC have fewer runways and significantly fewer boarding bridges and tend to be smaller (measured by their terminal size) ${ }^{4}$. Labor inputs, measured by employees directly employed by the airport operators, indicate that LAC airports have higher number of employees in smaller and relatively large airports while they have fewer employees in medium airports (5 to 8 million passengers per year).

[Table 2 app. here]

The paper first computes a data envelopment analysis (DEA) activity frontier for commercial airports in the LAC region and identifies the peers of each airport (i.e. comparable airports that operate on the efficiency frontier). We then proceed to measure Total Factor Productivity Changes (TFPC) for LAC airports over the period 2000-2007. The methodology used to perform these estimations consists on the computation of a Malmquist quantity index of TFPC based on the non-parametric DEA approach.

The paper is organized as follows. Section 2 presents a brief review of the existing related literature. In Section 3 we present calculations of a DEA activity frontier for commercial airports in the LAC region and use these results to identify their peers. Section 4 presents Malmquist quantity indexes of TFPC for LAC airports over the period 2000-2007. Section 5 presents some concluding remarks.

\footnotetext{
${ }^{4}$ To give an idea of the difference in investment in boarding bridges in LAC airports have on average 569,000 passengers per boarding bridge, compared with 359,000, 284,000 and 305,000 in Asia, Europe and North America respectively.
} 


\subsection{Literature Review}

Gillen and Lall (1997) pioneered the use of Data Envelopment Analysis techniques to study efficiency in the airport sector. Their paper uses data from 21 US airports for the period 1989-1993. Using this dataset they define airports as producing two different classes of services - terminal services and movements - and then proceed to compute two different DEA frontiers, one for each of these two services.

DEA is a deterministic non parametric approach used to build a benchmark, best practice frontier, based on available information. The method was first developed by Farrel (1957) and later consolidated by Charnes et al (1978). One of the main advantages of this approach is that it takes into account the multi-output multi-input dimensionality of production. Another advantage is that computations are based exclusively on measures of physical outputs and inputs, without the need of using prices, which are neither available nor are comparable, mainly at the international level.

Following Gillen and Lall (1997), a literature flourished using DEA methods to study the technical efficiency of the airport sector. In what follows we do not attempt to provide a complete account of this literature. Instead, we review the set of existing papers that is the most relevant for our paper. For a more complete and comprehensive account we refer the reader to Pestana Barros and Dieke (2008) ${ }^{5}$.

Using a Malmquist total factor productivity index and DEA, Abbot and Wu (2002) investigate the efficiency and productivity of Australian airports during the 1990s. Their results show that Australian airports recorded strong growth in technological change and total factor

\footnotetext{
${ }^{5}$ Some other examples not mentioned in the main text are Gillen and Lall (2001), Murillo-Melchor (1999) and Fung et al (2008).
} 
productivity during this period. However, this growth was based almost exclusively on a shift of the production frontier, with growth in technical and scale efficiency lagging behind.

A few papers study the efficiency of airports in Latin America. For example, Flor and de la Torre (2008) use DEA methods to analyze efficiency and total factor productivity of airports in Peru. Similarly, Fernandes and Pacheco (2002) employ DEA methods to compute a production frontier using data for Brazilian airports and Gomez Lobo and Gonzalez (2008) also employ DEA to compare one airport in LAC (Benito Merino airport, Santiago, Chile) with a set of airports in other regions. However, these papers focus on the efficiency of the airport sector in one single Latin American country. Indeed, to the best extent of our knowledge, this paper is the first that computes an efficient frontier for a representative sample of airports in the Latin American region. As such, this paper does not provide methodological innovations to estimate efficiency in the airport sector. It uses proven methodologies to calculate efficiency based on a unique dataset.

Given the trend towards the introduction of private sector participation in the airport sector, one of the variables we are interested in testing is the effect that ownership has on airport efficiency. There are other papers that study this issue. For example, using DEA methods Parker (1999) analyses the effect that privatization had on the efficiency level of British airports and finds that privatization had no noticeable impact on technical efficiency. Based on panel data for the major airports in Asia-Pacific, Europe and North America for the years 2001-2003, Oum, Adler and Yu (2006) study the effect that the type of ownership has on productive efficiency and profitability. Their results suggest that airports with government majority ownership and those owned by multi-level government are significantly less efficient than airports operating under private majority ownership. 
It should be noted that DEA is not the only methodology available that can be used to study the efficiency of the airport sector. ${ }^{6}$ Indeed, some authors have studied productivity in this sector through methods different than DEA. For instance, Hooper and Hensher (1997) use index number methods to study the evolution of total factor productivity of Australian airports for the period 1988-1992. Oum, Yan and Yu (2008) study the effects of ownership types on airports' cost efficiency by applying stochastic frontier analysis to a panel data of the world's major airports. Pestana Barros (2008) also uses stochastic frontier analysis to study the technical efficiency of airports in the UK. Finally, analyzing the efficiency of European airports, Pels, Nijkamp and Rietveld (2001) compare the results they get from DEA methods to the results obtained using stochastic frontier analysis. Their analysis shows that the stochastic frontier model they consider reproduces the DEA results in quite a reasonable way.

The use of DEA has certain limitations being the most important the fact that the inefficient units and their corresponding benchmarks may not be inherently similar which may result in inappropriate targets for improvement. In addition each unit may have a multiplicity of benchmark units and DEA can not inform which of the benchmark unit on the efficiency frontier is the first best target to follow (Sarkis and Talluri, 2004). An ideal extension of this paper should be the comparison of our results with those obtained using different methodologies. The main constraint to this task lies in the availability of data, in particular variables expressed in monetary terms, which are difficult to compare in a region that is subject to significant fluctuations in the exchange rate and with no uniform accounting methodology.

\footnotetext{
${ }^{6}$ For a complete and updated presentation of frontier analysis methods proposed in the literature, see Coelli et al. (2005) and Fried, Lovell and Schmit (2008).
} 


\subsection{Computing a Technical Efficiency Frontier for Airports in Latin America}

In this section we compute a DEA activity frontier for commercial airports in the LAC region using data for the period 2000-2007 from 21 LAC airports. Two models are computed under the competing assumptions of constant returns to scale (CRS) and variable returns to scale (VRS). This allows us to compute scale efficiencies and to identify for each airport the returns to scale region - increasing, constant or decreasing - in which it operates. We assume that airports have as production target the maximization of outputs for a given input combination; therefore, we use an output oriented framework ${ }^{7}$.

Frontier models like DEA require the specification of inputs and outputs used in the industry under study. There have been considerable differences in the literature of airport efficiency estimation at the time of defining inputs and outputs. On the output side the most common specification includes three output dimensions: passenger, freight and aircraft movements. On the inputs side there is fewer consensuses in the literature, mainly due to data availability problems. In any case, most studies include a bundle of variables representing labor and capital inputs. The most frequently used variables are the number of employees as proxy for labor input and capital proxies such as the number or size of runways, terminal size and the number of boarding bridges. When comparable accounting data is available, inputs are represented by operating costs and the monetary value of the capital stock ${ }^{8}$.

\footnotetext{
${ }^{7}$ For a description of the the linear programs (LP) used to compute TE-VRS and TE-CRS we refer the reader to Coelli (1996) and Coelli et.al (2005).

${ }^{8}$ As is the case in most airports benchmarking studies our results are subject to potential biases due to the difficulty associated with identifying outsourcing activities accurately. The use of outsourcing in the airport sector is heterogeneous. Our data set compiles direct employment by the airport operator. Given that we are measuring productive efficiency, under reporting of employment should be a smaller problem than when measuring quality of service. A somewhat similar problem might arise with the input terminal size if part of the terminal is used for activities not strictly related to the provision of aeronautical services. Most likely we have biases on the calculation
} 
In our case, and given the data at our disposal, we chose to specify a three-input threeoutput production function. The outputs that we use are (i) number of passengers, (ii) tons of freight and (iii) number of aircraft movements while the inputs are: (i) number of employees, (ii) number of runways and (iii) terminal size.

The dataset is not well balanced for the 21 LAC airports for the entire period (20002007). Given that 3 airports in the sample provided information only from 2004 to 2007, we opted to have two sub-periods of four years (2000-2003 and 2004-2007), with 18 and 21 airports respectively. Having the two sub-periods allows us to calculate the evolution in technical efficiency and total factor productivity change.

The computed Technical Efficiency (TE) scores for airports in Latin America are presented in Table 3. ${ }^{9}$ All variables, outputs and inputs, are averaged over the four-year periods 2000-2003 and 2004-2007. In this way, the results are less dependent both from unexpected demand shocks (e.g. 2001 September $11^{\text {th }}$ ) and from temporary productivity shocks due to major airport reforms (e.g. adding a new runway or a new terminal).

The average TE score, under constant returns to scale (CRS) and for the period 20042007 when the 21 airports are included in the sample, is 0.734 . This means that, on average, the airports included in the sample are three quarters technically efficient or, in other words, that they could increase their outputs by $25 \%$ using the same quantity of inputs. However, part of the distance to the best practice CRS frontier is explained by the scale of operation. Under the variable returns to scale (VRS) assumption the average TE is 0.826 . Therefore the average scale efficiency (SE) is 0.896 . For each scale inefficient airport it is possible to identify the type of

of technical efficiency that run in opposite direction: (a) downward bias caused by underreporting of employment and (b) upward biased due to reporting of terminal area larger than the one used to provide aeronautical services. ${ }^{9}$ All DEA computations, including Malmquist indexes presented in Section 4, were performed using the DEAP and FEAR programs developed by Coelli (1996) and Wilson (2008) respectively. 
scale inefficiency: either increasing or decreasing returns to scale, denoted in Table 3 as 'irs' and 'drs', respectively. Scale inefficiency of LAC airports for the period 2004-2007 is mainly concentrated in the increasing returns to scale area (11 over 21 airports). This means that, on average, airports in LAC could improve their efficiency by $10 \%$ if they were to increase its scale of operation to the optimal scale ${ }^{10}$. The results of return to scale diagnosis coincided with the intuition: airports in LAC tend to be small and given that the production technology of airports is characterized by large fixed investments (runways, terminals) it is logical to expect that smaller airports are still in the increasing return to scale zone of the production function ${ }^{11} 12$.

[Table 3 app. here]

Table 3 shows that 5 airports in the region are technically efficient under both CRS and VRS in the period 2000-2003 while this number increases to 6 in the period 2004-2007 ${ }^{13}$. If the scale of operation is not entirely under the control of airports managers, a fairly reasonable assumption, the TE-VRS results deserve detailed consideration. In this case the TE of LAC airports improve. Out of 21 airports in the period 2004-2007 12 are on the frontier. A comparison

\footnotetext{
${ }^{10}$ It is very difficult for airports to easily increase the scale of operations. A significant share of the demand (outputs) is exogenous.

${ }^{11}$ Airports identified as operating at the optimal scale (CRS) in our database handle between 2.5 to 25 million passengers per year (the largest airport in our sample by passengers is Benito Juarez in Mexico City with 25 million passengers in 2007). This result is consistent with previous estimates in the literature that found that the segment of constant returns to scale starts around the 3 million mark (Doganis, 1993). Tolofari et al (1990) found scale economies until 20 million work load units while Martin and Voltes-Dorta (2010) finds that economies of scale are unexhausted.

12 The results presented here were confirmed using the bootstrapping method proposed by Simar and Wilson (1998) and the FEAR software developed by Wilson (2008). The Spearman correlation between DEA TE scores computed with the original sample and those computed using the data generated by a smooth bootstrap re-sampling (400 replications) procedure were in all cases higher than 0.90 .

${ }^{13}$ It is important to highlight that VCP is a special case: it is an efficient unit in DEA 'by default', which occurs when a production unit has no peers to which it can be compared. VCP is an airport that can be characterized as a dedicated freight airport as it has virtually no passenger movements until 2007.
} 
of the evolution of TE-VRS scores across the two periods shows that most airports improve and even become part of the efficiency frontier (San Jose airport in Costa Rica, SJO, and Guadalajara airport in Mexico, GDL). Different is the case of the airport in Brasilia, Brazil (BSB) that suffers a notable decrease in its TE scores, a change that is explained by the growth in its inputs between periods (from one to two runways, from 60 thousand to 90 thousand square meters of terminal size and from 320 to 360 employees) that surpassed the growth of outputs.

As is the case whenever international comparisons among airports are made, in particular when efficiency is compared, care must be exercised when interpreting the results (UK Civil Aviation Authority, 2000 and Adler et.al, 2009). Airports operate under very different environments and subject to different sets of regulations. Differences in the operational approaches followed by airports could influence the results.

The use of DEA allows the identification of peers for each airport, which are the set of efficient airports that make up the relevant frontier for a given airport. Table 4 presents the peers for LAC airports for the period 2004-2007 under the CRS model. It should be noted that, by construction, technically efficient airports do not have other airport as peers but they act as peers for other, technical inefficient airports. Technical inefficient airports have, on the contrary, a benchmark composed by other units. Given the 3-output 3-inputs dimensionality of the production setting, the maximum number of peers is 6 but in the case presented here none of the airports have more than 4 peers.

Santiago de Chile (SCL) and Congonhas/São Paulo (CGH) are the airports in LAC that serve more frequently as peer for other airports, with 12 instances both. Other airports playing the same role of peers are VCP (Viracopos, São Paulo), GDL (Guadalajara, Mexico) and MEX (Benito Juarez, Mexico City). 
For illustration purposes we present the case of GIG (Aeroporto Antonio Carlos Jobim, Galeão/Rio de Janeiro). For this airport we computed a TE-CRS score of 0.347 , which corresponds to a $65 \%$ output inefficiency diagnosis. The airport identified as peer for GIG is MEX. If we compare GIG against MEX and look at some of their main output-input features (average of the period 2004-2007), we get a confirmation of the DEA result which indicates GIG is significantly more technical inefficient than MEX. On the output side GIG handled 8.4 million passengers per year, against 24.3 million passengers of MEX. Similarly, GIG had 101.6 thousand aircraft movements in 2005, against 335 thousand aircraft movements in MEX. On the input side GIG and MEX had 2 runways but GIG had 1482 employees (280 more than MEX) and a terminal of 394 thousand square meters (almost 64 thousand more than MEX).

[Table 4 app. here]

\section{0 Measuring Productivity Change of Latin American Airports}

The objective of this section is to assess how airport productivity evolved in Latin America. To that end we compute annual total factor productivity change (TFPC) for LAC airports over the period 2000 to 2007. As indicated before, we opted to divide the data in two sub-periods of four years each (2000-2003 and 2004-2007) to compute the growth in total factor productivity ${ }^{14}$. The calculation relies on the same 3-output 3-input model specification used in the calculation of technical efficiency scores of section 3 and the methodology consists in the

\footnotetext{
${ }^{14}$ The difference in the quantity of airports in the two sub-period is explained by data availability. Consequently, we had to restrict the database to 18 airports, leaving out Guayaquil (GYE), Lima (LIM) and Santo Domingo (SDQ).
} 
computation of a Malmquist quantity index of TFPC based on the non-parametric DEA approach.

Figure 1 illustrates the computation of the Malmquist index in a simple one-output (y) one-input (x) setting. Assuming constant returns to scale, the best practice technologies for period $s$ and period $t$ are defined by the period $s$ and $t$ DEA frontiers, respectively. The quantities of input and output of a particular unit in periods $s$ and $t$ are defined by points $\left(y_{s}, x_{s}\right)$ and $\left(y_{t}, x_{t}\right)$, respectively. Thus the distance of the unit in period $t$ relative to the period $t$ frontier is equal to $y_{t} / y_{d}$ and the distance in period $s$ relative to the period $t$ frontier is equal to $y_{s} / y_{b}$. Using this information and the distances computed relative to the period $t$ frontier, $y_{t} / y_{c}$ and $y_{s} / y_{a}$ the total factor productivity change (TFPC) Malmquist index is computed as follows:

$$
T F P C=\left[\frac{y_{t} / y_{d}}{y_{s} / y_{b}} \times \frac{y_{t} / y_{c}}{y_{s} / y_{a}}\right]^{0.5} .
$$

The Malmquist index of TFPC presents two advantages with respect to traditional index numbers. On the one hand prices are not needed to calculate this index. On the other hand, the index can be decomposed into a measure of technical change (TC) of the activity level taken as a whole, and technical efficiency change (TEC) that captures how each unit is catching up with respect to the technological frontier. From equation (1), TFPC is straightforward decomposed as follows:

$$
T F P C=T C \times T E C=\left[\frac{y_{t} / y_{c}}{y_{t} / y_{d}} \times \frac{y_{s} / y_{b}}{y_{s} / y_{a}}\right]^{0.5} \times \frac{y_{t} / y_{d}}{y_{s} / y_{a}} .
$$


The main disadvantage of the Malmquist index compared with traditional index numbers is that it cannot be computed separately for each unit. Its computation relies on the estimation of sequential frontiers. Thus, panel data must be available for benchmarking purposes. ${ }^{15}$

[Figure 1 app. here]

Table 5 shows that the average productivity growth of Latin American airports was 3.7\% between the two periods. On an annualized basis, the average productivity growth was $0.91 \%$, explained by a positive rate of technical efficiency change (a movement towards the efficiency frontier, or "catching-up”) of $14.6 \%$ (3.5\% per year). The fact that the calculated technical change between the two periods shows a result lower than 1 , indicates that the efficient frontier regressed by $9.5 \%$ (a negative rate of $2.5 \%$ per year).

[Table 5 app. here]

Twelve out of the eighteen airports in the sample show a positive rate of total factor productivity change. Taking out the small airport of El Calafate (FTE) in Argentina, that experienced a TFP change of $130 \%$ in the period due mainly to an increase in passengers form an average of 50,000 (2000-2003) to 180,000 (2004-2007), the airports in the sample show an average TFP change of $14.1 \%$ (3.4\% per year). When the analysis is made for those countries

\footnotetext{
${ }^{15}$ The reader is referred to Färe et al (1994) for details on the methodology, including its decomposition.
} 
with more than one airport in the sample, Mexico presents positive TFP change rates for all airports while Colombia has negative rates. Argentina and Brazil both show significant variation across airports. Viracopos airport (VCP) presents the highest negative rate of TFP change, explained entirely by a contraction of the frontier due to a slight increase in outputs (from 731 thousand passengers to 841 thousand and 205 thousand tons of cargo to 208 thousand between periods) and a notable increase in inputs (same number of runways, 1, but an increase from 365 to 701 employees and an increase in terminal size from 10 thousand square meters to 32 thousand).

A relevant policy question is whether privately operated airports in LAC, a region that has experienced with a wide variety of private sector participation schemes for the operation of airports, had higher productivity gains than airports operated by a public entity. Table 6 sheds some light to this question as it presents changes in productivity dividing airports by type of ownership ${ }^{16}$.

[Table 6 app. here]

Private airports performed better on average over the period 2000-2007 than public airports (annual positive productivity changes of $2.8 \%$ per year for private airports but negative rate of TFP of $0.9 \%$ for public airports). Mexican and Argentine airports in the sample are the drivers of the results for private operators, with annual TFP change rates of over $3 \%$ per year. On the contrary, Brazil drives the results for public airports, with a negative TFP rate of $2.7 \%$ per

\footnotetext{
${ }^{16}$ Table 6 presents unweighted results. The calculation using the Work Load Unit (equivalent to one terminal passenger or $100 \mathrm{~kg}$ of freight or mail) measure to weight airports and avoid reaching a conclusion on public/private operated airports biased by the size of airports show very similar results (differences in TFP change of less than $1 \%$ per year).
} 
years that is explained by a negative rate of technical change (it should be noted that Brazilian airports had a positive rate of technical efficiency change, implying that they are "catching up" to a shrinking frontier).

The results reported in Table 6 show that the medium size airports in LAC are the ones that registered faster productivity growth. In particular, those airports that handle between 5.0 and 8.0 million passengers per year posted an average annual growth rate of $1.5 \%$. Interestingly, this category is made up exclusively by privately operated airports (AEP, EZE, GDL, MTY and SCL).

The results reported in Table 6 were evaluated applying the sensitivity analysis, bootstrapping method, introduced by Simar and Wilson (1999). Using FEAR (Wilson, 2008), we compute $10 \%$ confidence intervals for each Malmquist TFP change observation in the sample. And using this information we distinguish observations with significant positive TFP change (>1.0), those with upper and lower confidence interval boundaries higher than 1.0, those with significant negative TFP change $(<1.0)$, those having lower and upper boundaries lower than 1.0, and finally observations with no TFP change correspond to cases where the confidence interval includes the value of unity. The result of this sensitivity analysis showed a high correlation in TFPC scores with the results presented in Tables 5 and 6. Only in three cases, CUN, EZE and SCL, the sign of total factor productivity change is undetermined but the average results by size and for public and private airports was confirmed. Nevertheless, the decomposition between technical efficiency change (TEC) and technical change (TC) were not confirmed. 


\subsection{Conclusions}

To the best extent of our knowledge, this paper is the first to conduct a comprehensive efficiency calculation of Latin American airports. The methodology used, Data Envelopment Analysis, allows the identification of the most efficient airports (i.e airports on the technological frontier) but it also identifies for each inefficient airport the set of peer airports that make up the relevant frontier for which it should be compared. To complement the calculation of the productive frontier we calculated a measure of productivity to know understand how the productive efficiency of each airport in the sample evolved in the period 2000-2007.

Our results indicate that technical efficiency in Latin American airports shows notable variations: from airports on the frontier (with a value of 1 ) to airports that have technical efficiency scores close to 0 . When variable returns to scale are assumed (which implies that the scale of operation is not entirely under the control of airport managers, a sensible assumption) of the 21 LAC airports in the sample, 12 are on the frontier.

Latin America has put in place different schemes to incorporate private sector participation in the management of airport infrastructure. The results obtained in this paper indicate that between the periods 2000 to 2003 and 2004 to 2007 private airports outperformed publicly operated airports with Total Factor Productivity growth rates of $+2.8 \%$ and $-0.9 \%$ respectively. When analyzed by size, small and middle size airports (less than 8 million passengers per year) experienced higher rates of Total Factor Productivity growth.

The results of the paper as well as its elaboration process provide several policy recommendations, being the most important the need to improve the generation of publicly available information and the quality of economic regulation in the LAC airport sector. 
Higher-quality regulation will call for consistent data collection and analysis, allowing for the generation of a robust and well-grounded benchmark of airport performance that highlights best performers. Better analysis will make it possible to determine whether policies (introduction of private sector participation, expansion of capacity, changes in the level of tariffs) achieve the desired objectives. A strong foundation of information will increase the quality of decision-making, thereby reducing the unpredictability of regulatory decisions and consequently the cost of capital. National efforts to strengthen airport regulation will be most effective if supported by the knowledge and experience of established institutions, such as the Airport Council International (ACI) and the International Civil Aviation Organization (ICAO).

A natural extension of the paper would be to study the determinants of the calculated technical efficiency scores. Likely candidates to be the main drivers of technical efficiency include airport characteristics (hub, share of international and connecting passengers, share of aeronautical revenues), socioeconomic environment (GDP per capita and tourism expenditure in the relevant geographic market), institutional framework (type of ownership, existence of independent regulator) and population concentration (population in the cities served by the airport).

Further research should explore alternative methodologies to measure efficiency and collect information on the quality of service provided, as this is a major determinant of airports' costs and a key input for strengthening programs aimed at increasing competitiveness and growth through tourism, industry, and clusters development or high-value-added air cargo trade... 


\section{Acknowledgments}

We are grateful to Germà Bel for the comments he provided as discussant in the International Conference on Infrastructure and Development, Toulouse, 2010 and those provided by two anonymous referees. Juan Ortner and Matías Herrera Dappe provided excellent research assistance. The financial support given by PPIAF is acknowledged. All errors are exclusively our own. 


\section{References}

Abbot, M. and S. Wu (2002), "Total Factor Productivity and Efficiency of Australian Airports”, The Australian Economic Review, 35, 244-60.

Adler, N., Oum, T. H., and Yu, Ch (2009), “A Response to 'Understanding the Complexities and Challenges of Airport Performance Benchmarking’”, Journal of Airport Management, Vol. 3, Issue 2, 159-163.

Air Transport Research Society (2008). Airport Benchmarking Report. Global Standards for Airport Excellence. University of British Columbia, Canada.

Charnes, A., W. W. Cooper, and E. Rhodes (1978), "Measuring the Efficiency of DecisionMaking Units”, European Journal of Operations Research, 2, 429-444.

Civil Aviation Authority (2000), “The use of benchmarking in the airport reviews”, Consultation paper, CAA, London.

Coelli, T.J. (1996), “A Guide to DEAP Version 2.0: A Data Envelopment Analysis (Computer) Program”, CEPA Working Paper 96/08, Universtity of New England, Armidale.

Coelli, T.J., D.S.P. Rao, C.J. O’Donnell and G.E. Battese (2005), An Introduction to Efficiency and Productivity Analysis, $2^{\text {nd }}$ Edition, Springer, New York.

Doganis, R (1993). The Airport Business. Routledge, London.

Fernandes, E. and R. R. Pacheco (2002), “Efficient use of Airport Capacity”, Transportation Research Part A, 36, 225-238. 
Fried, H., Lovell, K. C. A. and S. S. Schmidt (eds.) (2008), The Measurement of Productive Efficiency and Productivity Growth, Oxford University Press.

Flor, L. and B. de la Torre (2008), “Medición no Paramétrica de Eficiencia y Productividad total de los Factores: El Caso de los Aeropuertos Regionales de Perú”, Revista de Regulación en Infraestructura de Transporte, Vol 1, 100-115.

Fung, M. K. Y., K. K. H. Wana, Y. V. Huia and J. S. Lawa (2008), "Productivity Changes in Chinese Airports 1995-2004”, Transportation Research Part E, 44, 521-542.

Gomez-Lobo, A. and Gonzalez, A (2008). “The use of airport charges for funding general expenditures: The case of Chile”, Journal of Air Transport Management, 14, 308-314.

Gillen, D. and A. Lall (1997), “Developing Measures of Airport Productivity and Performance: An Application of Data Envelopment Analysis”, Transportation Research Part E, 33, 261-273.

Gillen, D. and A. Lall (2001), “Non-Parametric Measures of Efficiency of US Airports”, International Journal of Transport Economics, 28, 2083-306.

Hooper, P. G. and D. A. Hensher (1997), "Measuring Total Factor Productivity of Airports - An Index Number Approach”, Transportation Research Part E, 33, 249-259.

Murillo-Melchor, C. (1999), “An Analysis of Technical Efficiency and Productive Change in Spanish Airports Using Malmquist Index”, International Journal of Transport Economics, 26, 271-292.

Oum, T. H., J. Yan and C. Yu (2008), “Ownership Forms Matter for Airport Efficiency: A Stochastic Frontier Investigation of Worldwide Airports”, Journal of Urban Economics, 64, 422-435. 
Oum, T. H., N. Adler and C. Yu (2006), "Privatization, Corporatization, Ownership Forms and their Effects on the Performance of the World's Major Airports”, Journal of Air Transport Management, 12, 109-121.

Parker, D. (1999), “The Performance of BAA Before and After Privatization: A DEA Study”, Journal of Transport Economics and Policy, 33, 133-146.

Pels, E., Nijkamp P. and Rietveld, P (2001), "Relative Efficiency of European Airports", Transport Policy, 8, 183-192.

Pestana Barros C. and P. U. C. Dieke (2008), "Measuring the Economic Efficiency of Airports: A Simar-Wilson Methodology Analysis”, Transportation Research Part E, 44, 1039-1051.

Pestana Barros, C. (2008), “Technical Efficiency of UK Airports”, Journal of Air Transport Management, 14, 175-178.

Sarkis, J., and Talluri, S (2004), "Performance based clustering for benchmarking US airports”, Transportation Research A 38, 329-346.

Simar, L. and P. W. Wilson (1998), “Sensitivity analysis of efficiency scores: How to bootstrap in nonparametric frontier models”, Management Science, 44, 49-61.

Simar, L. and P. W. Wilson (1999), "Estimating and bootstrapping Malmquist indices”, European Journal of Operational Research, 115, 459-471.

Simar, L. and P. W. Wilson (2007), “Estimation and Inference in Two_stage, Semi-Parametric Models of Productive Efficiency”, Journal of Econometrics, 136, 31-64. 
Wilson, P. W. (2008), “FEAR 1.0: A software Package for Frontier Efficiency Analysis with R”, Socio-Economic Planning Sciences, 42, 247-254.

World Bank (2010). Airport Benchmarking in Latin America. Mimeo. Washington. D.C 


\section{Figures and tables}

Table 1: Airports in Latin American and Caribbean Airports included in the sample

\begin{tabular}{|c|c|c|c|}
\hline City, Country & Airport Name (Code) & $\begin{array}{c}\text { Type of } \\
\text { Ownership } \\
\text { (2008) }\end{array}$ & $\begin{array}{l}\text { Passengers } \\
\text { in } 2008\end{array}$ \\
\hline $\begin{array}{l}\text { Buenos Aires, } \\
\text { Argentina }\end{array}$ & Aeroparque Jorge Newbery (AEP) & Private & $5,687,221$ \\
\hline $\begin{array}{l}\text { Buenos Aires, } \\
\text { Argentina }\end{array}$ & Aeropuerto Ministro Pistarini (EZE) & Private & $8,012,794$ \\
\hline El Calafate, Argentina & Aeropuerto El Calafate (FTE) & Private & 494,722 \\
\hline São Paulo, Brazil & Aeroporto de São Paulo /Congonhas (CGH) & Public & $13,661,227$ \\
\hline São Paulo, Brazil & Aeroporto de Viracopos (VCP) & Public & $1,260,112$ \\
\hline São Paulo, Brazil & $\begin{array}{l}\text { Aeroporto de São Paulo/Guarulhos Governador Andre } \\
\text { Franco Montoro (GRU) }\end{array}$ & Public & $20,990,662$ \\
\hline Brasilia, Brazil & Aeroporto de Brasilia Presidente Juscelino Kubitschek (BSB) & Public & $10,892,330$ \\
\hline Manaus, Brazil & Aeroporto Eduardo Gomes (MAO) & Public & $1,957,050$ \\
\hline Rio de Janeiro, Brazil & $\begin{array}{l}\text { Aeroporto de Rio de Janeiro/Galeão Antonio Carlos Jobim } \\
\text { (GIG) }\end{array}$ & Public & $10,695,992$ \\
\hline $\begin{array}{l}\text { Santiago de Chile, } \\
\text { Chile }\end{array}$ & Aeropuerto Comodoro Arturo Merino Benítez (SCL) & Private & $9,017,718$ \\
\hline Cali, Colombia & Aeropuerto Alfonso Bonilla Aragón (CLO) & Private & $2,418,644$ \\
\hline $\begin{array}{l}\text { Barranquilla, } \\
\text { Colombia }\end{array}$ & Aeropuerto Ernesto Cortissoz (BAQ) & Private & $1,207,084$ \\
\hline San José, Costa Rica & Aeropuerto Juan Santamaría (SJO) & Private & $3,238,602$ \\
\hline Guayaquil, Ecuador & Aeropuerto José Joaquín de Olmedo (GYE) & Private & $3,236,768$ \\
\hline $\begin{array}{l}\text { San Salvador, El } \\
\text { Salvador }\end{array}$ & Aeropuerto de El Salvador (SAL) & Public & $1,570,012$ \\
\hline Guadalajara, Mexico & Aeropuerto de Guadalajara (GDL) & Private & $7,393,500$ \\
\hline Monterrey, Mexico & Aeropuerto General Mariano Escobedo (MTY) & Private & $6,749,240$ \\
\hline Mexico City, Mexico & Aeropuerto Benito Juárez (MEX) & Public & $26,210,217$ \\
\hline Cancun, Mexico & Aeropuerto de Cancún (CUN) & Private & $12,786,423$ \\
\hline Lima, Peru & Aeropuerto Jorge Chávez (LIM) & Private & $8,285,688$ \\
\hline $\begin{array}{l}\text { Sto. Domingo, } \\
\text { Dominican Republic. }\end{array}$ & Aeropuerto de Las Américas (SDQ) & Private & $2,719,899$ \\
\hline
\end{tabular}

Note: Private ownership in the context of Latin America should be understood as a concession to a private operator. The underlying asset remains under Government ownership. Public ownership: all airports in the sample under operation of a state-owned firm. 
Table 2: Comparison of the airport sector in Latin America with other regions (2006)

\begin{tabular}{|c|c|c|c|c|c|}
\hline \multirow{2}{*}{ Variables } & \multicolumn{4}{|c|}{ Passengers per year (millions) } & \multirow{2}{*}{ All } \\
\hline & $<5.0$ & $5.0-8.0$ & $8.0-25.0$ & $>25,0$ & \\
\hline \multicolumn{6}{|c|}{ Latin American and Caribbean Airports (LAC) } \\
\hline Airports in sample & 9 & 6 & 6 & 0 & 21 \\
\hline Share (\%) & 42.9 & 28.6 & 28.6 & & 100.0 \\
\hline \multicolumn{6}{|l|}{ Outputs-Inputs } \\
\hline Passenger $(1,000)$ & 1,804 & 6,257 & 14,538 & & 6,715 \\
\hline Aircraft movements $(1,000)$ & 39 & 93 & 197 & & 100 \\
\hline WLU / Aircraft movement & 2,510 & 7,647 & 16,228 & & 7,898 \\
\hline Employees & 277 & 229 & 895 & & 440 \\
\hline Runways & 1.1 & 1.5 & 1.8 & & 1.4 \\
\hline Airport surface (thous. of sq meters) & 39.6 & 57.1 & 187.3 & & 86.8 \\
\hline Boarding bridges & 5.7 & 9.3 & 21.2 & & 11.1 \\
\hline \multicolumn{6}{|l|}{ Airport characteristics } \\
\hline Passenger connecting (\%) & 8.0 & 3.5 & 6.2 & & 6.1 \\
\hline Aeronautical revenues (\%) & 53.8 & 59.7 & 56.3 & & 56.3 \\
\hline \multicolumn{6}{|c|}{ Europe, North America and Asia-Pacific Airports } \\
\hline Airports in sample & 15 & 11 & 53 & 39 & 118 \\
\hline Share (\%) & 12.7 & 9.3 & 44.9 & 33.1 & 100.0 \\
\hline \multicolumn{6}{|l|}{ Outputs-Inputs } \\
\hline Passenger $(1,000)$ & 3,245 & 6,309 & 14,695 & 40,569 & 21,009 \\
\hline Aircraft movements (1.000) & 61 & 105 & 204 & 419 & 248 \\
\hline WLU / Aircraft movement & 5,132 & 7,434 & 17,544 & 49,978 & 25,744 \\
\hline Employees & 260 & 314 & 811 & 2,101 & 1,121 \\
\hline Runways & 1.7 & 2.4 & 2.7 & 3.5 & 2.8 \\
\hline Airport surface (thous. of sq meters) & 51.0 & 73.2 & 132.9 & 389.8 & 201.8 \\
\hline Boarding bridges & 15.9 & 27.4 & 56.7 & 109.9 & 66.4 \\
\hline \multicolumn{6}{|l|}{ Airport characteristics } \\
\hline Passenger connecting (\%) & 12.4 & 7.8 & 18.5 & 33.2 & 22.3 \\
\hline Aeronautical revenues (\%) & 54.7 & 46.3 & 48.4 & 49.9 & 49.5 \\
\hline
\end{tabular}

Source: Data for airports in Europe, North America and Asi-Pacific obtained from Air Transport Research Society Benchmarking Report (2008). Data for airports in Latin America obtained from World Bank questionnaires. 
Table 3: Technical and scale efficiency of Latin American airports (2000-2007)

\begin{tabular}{|c|c|c|c|c|c|c|c|c|c|}
\hline \multirow{2}{*}{ Country } & \multirow{2}{*}{ Airport } & \multicolumn{4}{|c|}{ 2000-2003 } & \multicolumn{4}{|c|}{ 2004-2007 } \\
\hline & & TE-CRS & TE-VRS & $\mathrm{SE}$ & RTS & TE-CRS & TE-VRS & SE & RTS \\
\hline \multirow{3}{*}{ Argentina } & AEP & 0.850 & 1.000 & 0.850 & irs & 0.652 & 1.000 & 0.652 & irs \\
\hline & EZE & 0.621 & 0.684 & 0.908 & drs & 0.773 & 0.851 & 0.908 & drs \\
\hline & FTE & 0.086 & 1.000 & 0.086 & irs & 0.215 & 1.000 & 0.215 & irs \\
\hline \multirow{6}{*}{ Brazil } & BSB & 0.953 & 1.000 & 0.953 & drs & 0.598 & 0.619 & 0.966 & irs \\
\hline & $\mathrm{CGH}$ & 1.000 & 1.000 & 1.000 & crs & 1.000 & 1.000 & 1.000 & crs \\
\hline & GIG & 0.307 & 0.319 & 0.962 & drs & 0.347 & 0.347 & 1.000 & crs \\
\hline & GRU & 0.877 & 1.000 & 0.877 & drs & 0.991 & 1.000 & 0.991 & drs \\
\hline & MAO & 0.558 & 0.579 & 0.963 & irs & 0.835 & 0.854 & 0.978 & irs \\
\hline & VCP & 1.000 & 1.000 & 1.000 & crs & 1.000 & 1.000 & 1.000 & crs \\
\hline Chile & SCL & 1.000 & 1.000 & 1.000 & crs & 1.000 & 1.000 & 1.000 & crs \\
\hline \multirow{2}{*}{ Colombia } & BAQ & 0.279 & 0.377 & 0.739 & irs & 0.330 & 0.427 & 0.774 & irs \\
\hline & CLO & 0.796 & 1.000 & 0.796 & irs & 0.856 & 1.000 & 0.856 & irs \\
\hline Costa Rica & SJO & 0.674 & 0.888 & 0.759 & irs & 0.903 & 1.000 & 0.903 & irs \\
\hline Ecuador & GYE & - & - & - & - & 0.632 & 0.859 & 0.735 & irs \\
\hline El Salvador & SAL & 0.189 & 0.225 & 0.838 & drs & 0.261 & 0.261 & 0.998 & drs \\
\hline \multirow{4}{*}{ Mexico } & CUN & 1.000 & 1.000 & 1.000 & crs & 1.000 & 1.000 & 1.000 & crs \\
\hline & GDL & 0.796 & 0.802 & 0.992 & irs & 1.000 & 1.000 & 1.000 & crs \\
\hline & MEX & 1.000 & 1.000 & 1.000 & crs & 1.000 & 1.000 & 1.000 & crs \\
\hline & MTY & 0.499 & 0.509 & 0.981 & irs & 0.682 & 0.697 & 0.979 & irs \\
\hline Peru & LIM & - & - & - & - & 0.972 & 1.000 & 0.972 & irs \\
\hline Dominican Rep. & SDQ & - & - & - & - & 0.357 & 0.428 & 0.834 & irs \\
\hline Average & & 0.694 & 0.799 & 0.872 & & 0.734 & 0.826 & 0.896 & \\
\hline
\end{tabular}


Table 4: Peer analysis, DEA-CRS 2004-2007

\begin{tabular}{|c|c|c|c|c|c|c|c|}
\hline \multirow{2}{*}{ Country } & \multirow{2}{*}{ Airport } & \multirow{2}{*}{ TE-CRS } & \multirow{2}{*}{$\begin{array}{l}\text { As peer } \\
\text { for other } \\
\text { airports }\end{array}$} & \multicolumn{4}{|c|}{ Peers } \\
\hline & & & & 1 & 2 & 3 & 4 \\
\hline \multirow{3}{*}{ Argentina } & AEP & 0.652 & 0 & MEX & SCL & CGH & \\
\hline & EZE & 0.773 & 0 & VCP & SCL & CGH & GDL \\
\hline & FTE & 0.215 & 0 & CGH & & & \\
\hline \multirow{6}{*}{ Brazil } & BSB & 0.598 & 0 & CGH & MEX & SCL & \\
\hline & CGH & 1.000 & 12 & CGH & & & \\
\hline & GIG & 0.347 & 0 & MEX & & & \\
\hline & GRU & 0.991 & 0 & SCL & MEX & CGH & \\
\hline & MAO & 0.835 & 0 & SCL & GDL & VCP & \\
\hline & VCP & 1.000 & 7 & VCP & & & \\
\hline Chile & SCL & 1.000 & 12 & SCL & & & \\
\hline \multirow[t]{2}{*}{ Colombia } & BAQ & 0.330 & 0 & SCL & VCP & GDL & $\overline{\text { CGH }}$ \\
\hline & CLO & 0.856 & 0 & CGH & SCL & & \\
\hline Costa Rica & SJO & 0.903 & 0 & VCP & SCL & GDL & \\
\hline Ecuador & GYE & 0.632 & 0 & SCL & VCP & CGH & \\
\hline El Salvador & SAL & 0.261 & 0 & GDL & VCP & CGH & \\
\hline \multirow{4}{*}{ Mexico } & CUN & 1.000 & 0 & CUN & & & \\
\hline & GDL & 1.000 & 6 & GDL & & & \\
\hline & MEX & 1.000 & 5 & MEX & & & \\
\hline & MTY & 0.682 & 0 & SCL & GDL & CGH & \\
\hline Peru & LIM & 0.972 & 0 & VCP & CGH & SCL & \\
\hline Dominican Rep. & SDQ & 0.357 & 0 & SCL & CGH & MEX & \\
\hline
\end{tabular}


Figure 2: The Malmquist index of productivity change

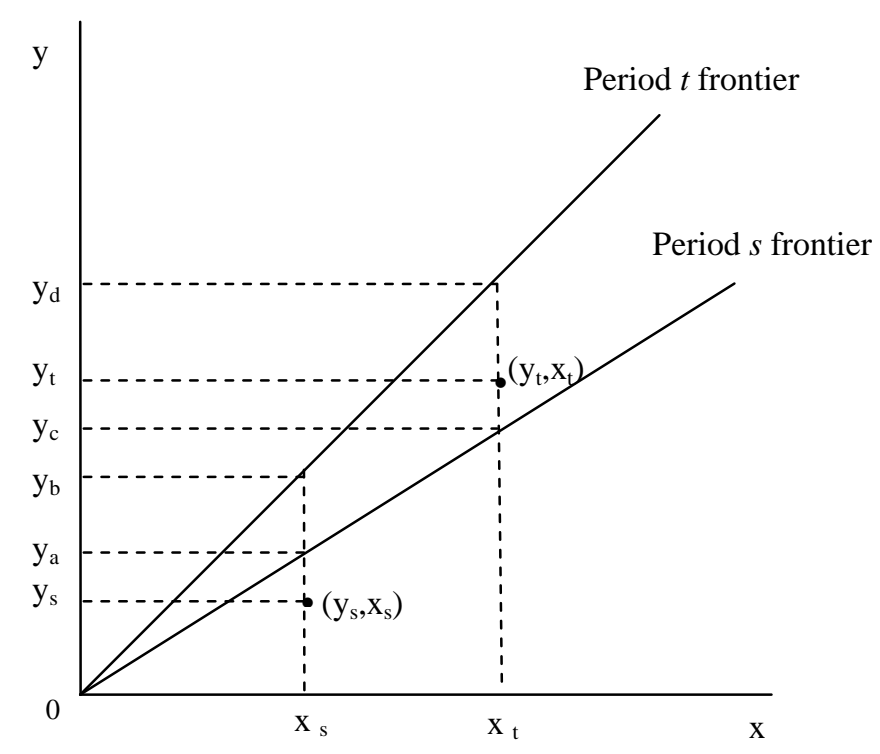


Table 5: TFP change 2004-2007 / 2000-2003

\begin{tabular}{|c|c|c|c|c|}
\hline Country & Airport & $\begin{array}{c}\text { TFP } \\
\text { change }\end{array}$ & $\begin{array}{c}\text { Technical } \\
\text { efficiency } \\
\text { change }\end{array}$ & $\begin{array}{c}\text { Technical } \\
\text { change }\end{array}$ \\
\hline \multirow{3}{*}{ Argentina } & AEP & 0.841 & 0.768 & 1.095 \\
\hline & EZE & 1.117 & 1.246 & 0.897 \\
\hline & FTE & 2.309 & 2.501 & 0.923 \\
\hline \multirow{6}{*}{ Brazil } & BSB & 0.670 & 0.628 & 1.068 \\
\hline & $\mathrm{CGH}$ & 0.864 & 1.000 & 0.864 \\
\hline & GIG & 1.271 & 1.129 & 1.126 \\
\hline & GRU & 1.148 & 1.130 & 1.016 \\
\hline & MAO & 1.209 & 1.497 & 0.808 \\
\hline & VCP & 0.514 & 1.000 & 0.514 \\
\hline Chile & SCL & 1.067 & 1.000 & 1.067 \\
\hline \multirow{2}{*}{ Colombia } & $\mathrm{BAQ}$ & 0.965 & 1.185 & 0.815 \\
\hline & CLO & 0.823 & 1.075 & 0.766 \\
\hline Costa Rica & SJO & 1.129 & 1.340 & 0.842 \\
\hline El Salvador & SAL & 1.099 & 1.378 & 0.797 \\
\hline \multirow{4}{*}{ Mexico } & CUN & 1.109 & 1.000 & 1.109 \\
\hline & GDL & 1.116 & 1.256 & 0.889 \\
\hline & MEX & 1.085 & 1.000 & 1.085 \\
\hline & MTY & 1.195 & 1.366 & 0.875 \\
\hline Average & & 1.037 & 1.146 & 0.905 \\
\hline
\end{tabular}


Table 4: TFP Average results by size and ownership

\begin{tabular}{|c|c|c|c|}
\hline \multirow[b]{2}{*}{$\begin{array}{c}\text { Airport } \\
\text { characteristics }\end{array}$} & \multicolumn{3}{|c|}{ Malmquist index } \\
\hline & $\begin{array}{c}\text { TFP } \\
\text { change }\end{array}$ & $\begin{array}{c}\text { Technical } \\
\text { efficiency } \\
\text { change }\end{array}$ & $\begin{array}{c}\text { Technical } \\
\text { change }\end{array}$ \\
\hline Size $\left(10^{6}\right)$ & & & \\
\hline$<5.0$ & 1.051 & 1.365 & 0.770 \\
\hline $5.0-8.0$ & 1.060 & 1.104 & 0.960 \\
\hline $8.0-25.0$ & 1.003 & 0.964 & 1.041 \\
\hline Ownership & & & \\
\hline Public & 0.962 & 1.092 & 0.881 \\
\hline Private & 1.118 & 1.202 & 0.930 \\
\hline All & 1.037 & 1.146 & 0.905 \\
\hline
\end{tabular}

Public airports: BSB, CGH, GIG, GRU, MAO and VCP (Brazil); SAL (El Salvador); MEX (Mexico). Private airports: AEP, EZE, FTE (Argentina); SCL (Chile), BAQ and CLO (Colombia); SJO (Costa Rica); CUN, GDL and MTY (Mexico).

Airport size: < 5.0: BAQ, CLO, FTE, MAO, VCP, SAL and SJO; 5.0-8.0: AEP, EZE, GDL, MTY and SCL; > 8.0: BSB, CUN, GIG, CGH, GRU and MEX. 